\title{
Vaccination with chemically attenuated Plasmodium falciparum asexual blood-stage parasites induces parasite-specific cellular immune responses in malaria-naïve volunteers: a pilot study
}

Danielle I. Stanisic 1*, James Fink², Johanna Mayer², Sarah Coghill², Letitia Gore², Xue Q. Liu', Ibrahim El-Deeb',

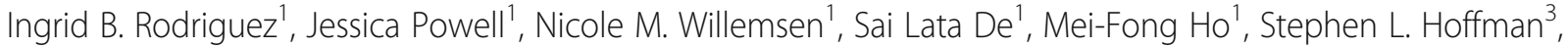
John Gerrard ${ }^{2}$ and Michael F. Good ${ }^{1 *}$

\begin{abstract}
Background: The continuing morbidity and mortality associated with infection with malaria parasites highlights the urgent need for a vaccine. The efficacy of sub-unit vaccines tested in clinical trials in malaria-endemic areas has thus far been disappointing, sparking renewed interest in the whole parasite vaccine approach. We previously showed that a chemically attenuated whole parasite asexual blood-stage vaccine induced $\mathrm{CD} 4^{+} \mathrm{T}$ cell-dependent protection against challenge with homologous and heterologous parasites in rodent models of malaria.

Methods: In this current study, we evaluated the immunogenicity and safety of chemically attenuated asexual blood-stage Plasmodium falciparum (Pf) parasites in eight malaria-naive human volunteers. Study participants received a single dose of $3 \times 10^{7} \mathrm{Pf}$ pRBC that had been treated in vitro with the cyclopropylpyrolloindole analogue, tafuramycin-A.

Results: We demonstrate that Pf asexual blood-stage parasites that are completely attenuated are immunogenic, safe and well tolerated in malaria-naiive volunteers. Following vaccination with a single dose, species and strain transcending Plasmodium-specific T cell responses were induced in recipients. This included induction of Plasmodium-specific lymphoproliferative responses, $T$ cells secreting the parasiticidal cytokines, IFN- $\gamma$ and TNF, and $\mathrm{CD}^{+}{ }^{+} \mathrm{CD} 45 \mathrm{RO}^{+}$ memory T cells. Pf-specific lgG was not detected.

Conclusions: This is the first clinical study evaluating a whole parasite blood-stage malaria vaccine. Following administration of a single dose of completely attenuated Pf asexual blood-stage parasites, Plasmodium-specific T cell responses were induced while Pf-specific antibodies were not detected. These results support further evaluation of this chemically attenuated vaccine in humans.
\end{abstract}

Trial registration: Trial registration: ACTRN12614000228684. Registered 4 March 2014.

Keywords: Malaria, Plasmodium falciparum, Vaccines, Chemically attenuated malaria parasites, T cell responses

\footnotetext{
*Correspondence: d.stanisic@griffith.edu.au; Michael.Good@griffith.edu.au

'Institute for Glycomics, Griffith University, Parklands Drive, Southport,

Queensland, Australia

Full list of author information is available at the end of the article
}

(c) The Author(s). 2018 Open Access This article is distributed under the terms of the Creative Commons Attribution 4.0 International License (http://creativecommons.org/licenses/by/4.0/), which permits unrestricted use, distribution, and reproduction in any medium, provided you give appropriate credit to the original author(s) and the source, provide a link to the Creative Commons license, and indicate if changes were made. The Creative Commons Public Domain Dedication waiver (http://creativecommons.org/publicdomain/zero/1.0/) applies to the data made available in this article, unless otherwise stated. 


\section{Background}

Plasmodium spp. parasites cause more than 200 million clinical cases of malaria and 438,000 deaths per year, with the majority of deaths occurring in children $<5$ years of age [1]. An effective vaccine capable of inducing long-lasting immunity is not currently available. Disappointing results following the testing of sub-unit vaccines in clinical trials [2-5] have highlighted some of the limitations of sub-unit vaccines that need to be addressed, including antigenic polymorphism in critical epitopes.

The limited protection induced by sub-unit vaccine candidates has resulted in renewed interest in the whole organism vaccine approach. The fundamental rationale for a whole parasite vaccine is that by maximising the number of antigens presented to the immune system, including those that are conserved between different parasite strains, the impact of antigenic polymorphism will be diminished. There has been considerable progress with injectable whole parasite Plasmodium falciparum sporozoite (PfSPZ) vaccines [6-11]. The administration of whole blood-stage parasites in the context of controlled human malaria infection (CHMI) in human volunteers is not new [12]; deliberate malaria infection was used as a treatment for neurosyphilis (malariotherapy) in the early 1900s (reviewed in [13, 14]). CHMI with whole blood-stage parasites is also used for the in vivo assessment of malaria vaccine and drug candidate efficacy (reviewed in [12]). However, there have been no published clinical studies of whole parasite blood-stage malaria vaccines [15].

Cyclopropylpyrolloindole analogues, such as centanamycin (CM) and tafuramycin-A (TF-A) have been used to successfully attenuate both sporozoite and asexual blood-stage malaria parasites [16-20]. These compounds bind covalently to poly-A regions of DNA [21]. Studies in mice involving vaccination with chemically attenuated sporozoites demonstrated induction of protective immunity $[16,17]$. To adapt this for a blood-stage vaccine approach, we vaccinated mice with a single dose of ring-stage Plasmodium chabaudi AS parasitised red blood cells ( $\mathrm{pRBC}$ ) that had been treated in vitro with $\mathrm{CM}$ or the related compound, TF-A, and demonstrated long-lasting protection from homologous and heterologous blood-stage challenge [18]. Similar protection was observed when mice were vaccinated with chemically attenuated Plasmodium yoelii 17X, although three doses of vaccine provided superior protection compared to one dose [19]. Although an adjuvant was not required for induction of protective immune responses, vaccine efficacy was ablated if the red cell membrane was disrupted [18]. These data suggested that the red cell membranes were required to target the attenuated parasites to dendritic cells in the spleen and liver, which was observed post-vaccination. Protective immunity was dependent on $\mathrm{CD}^{+} \mathrm{T}$ cells present at the time of challenge, and a strong IFN- $\gamma$ response was induced by the vaccine $[18,19]$. Parasite-specific antibodies were induced only in the $P$. yoelii $17 \mathrm{X}$ model and contributed to protection. Vaccination also led to a significant $\mathrm{CD}^{+} \mathrm{T}$ cell response, although depletion of these cells did not ablate vaccine-induced immunity. In previous pre-clinical studies involving other types of whole parasite blood-stage vaccines, it was shown that cellular immunity or IFN- $\gamma$ played critical roles in protection [22-24]. The importance of IFN- $\gamma$ in immunity to human malaria has also been demonstrated in individuals in malaria-endemic areas [25-28] and in a controlled human experimental infection study [29].

To facilitate transition of the chemically attenuated vaccine approach into humans, pre-clinical in vitro and in vivo studies with $P$. falciparum (Pf) were undertaken. Treatment of parasites with $2 \mu \mathrm{M} C M$ resulted in complete parasite attenuation in vitro [18]. In vivo studies in Aotus monkeys showed that following inoculation of TF-A-treated parasites, they persisted at sub-patent levels for up to 8 days (as determined by qPCR) [30]. Pf-specific T cell responses, but not Pf-specific IgG, were induced. Collectively, these data supported the evaluation of this vaccine approach in clinical studies.

We previously manufactured clinical-grade cultured Pf asexual blood-stage cell banks [31] and demonstrated their infectivity in vivo in malaria-naïve volunteers [32]. In this present study, we used the Pf 7G8 cell bank to investigate the immunogenicity, safety and tolerability of chemically attenuated parasites in malaria-naïve individuals.

\section{Methods}

\section{Aims and study participants}

The main aims of the study were to (i) characterise the safety and tolerability of TF-A-treated Pf blood-stage parasites in humans and to (ii) characterise the immunogenicity of TF-A-treated Pf blood-stage parasites in humans. Griffith University was the study sponsor, and the study was conducted in the Clinical Trial Unit at Griffith University, Southport, Queensland, Australia, from July 2014 to August 2015. Study participants were healthy male, malaria-naïve individuals, aged 18-60 years $(n=8)$ (Additional file 1: Table S1). Volunteers were excluded if they had a history of malaria infection or travelled to/lived ( $>2$ weeks) in a malaria-endemic country during the previous 12 months. Other key eligibility criteria can be found in the listing on the Australian New Zealand Clinical Trials registry (www.anzctr.org.au); the identifier is ACTRN12614000228684.

Study participants received a single vaccination of $3 \times$ $10^{7} \mathrm{pRBC}$ treated with $50 \mathrm{nM}$ of TF-A (group A; $n=3$ ) or $200 \mathrm{nM}$ of TF-A (group B; $n=5$ ) on study day 0 . Follow-up visits were scheduled every 2 days (from study 
day 2 to day 26) following vaccination. At these visits, blood samples were collected to assess parasite levels in the blood of participants and to evaluate the immunogenicity of the vaccine in established assays. If the numbers of parasites in the blood increased exponentially and levels reached 11,500 $\mathrm{pRBC} / \mathrm{ml}$ (as measured by quantitative PCR [qPCR]) or clinical symptoms of malaria developed, rescue treatment with a standard course of the anti-malarial artemetherlumefantrine $(\mathrm{A} / \mathrm{L})$ (Riamet) was commenced immediately. If rescue treatment with $\mathrm{A} / \mathrm{L}$ was not initiated, 4 weeks following administration of the vaccine (day 28), participants were given a standard course of $\mathrm{A} / \mathrm{L}$.

For safety assessments at every visit, participants were evaluated by a medical investigator. This included a physical exam, measurement of vital signs (e.g. temperature, heart rate, blood pressure and respiratory rate) and recording of solicited and unsolicited adverse events. Blood was also collected for safety purposes at designated scheduled visits (days $0,8,16,28,90$ ) for group B. For group A, this was undertaken at days 0,8 , the day of initiation of anti-malarial treatment for each participant (days 10-13), days 28 and 90. Sullivan Nicolaides Pathology tested samples collected prior to immunisation, on day 28 and day 90 for the presence of alloantibodies. Indirect anti-globulin testing was undertaken using column agglutination technology. An independent Safety Review Team, including an independent medical expert, was appointed to oversee the study and monitor its progress.

\section{Culture of Pf for the production of chemically treated parasites}

The culturing of Pf 7G8 for the production of chemically treated parasites was undertaken at Griffith University. All processes were carried out in compliance with Annex 13, Pharmaceutical Inspection Co-operation Scheme (PIC/S) Guide, in a monitored environment suitable for production of sterile biologics in accordance with approved protocols. For group A (P1, P2, P3) and three participants in group B (P4, P5, P6), cultures were initiated using seed vials from the clinical-grade Pf 7 G8 cell bank [31] and were expanded using leukocyte-depleted group $\mathrm{O} \mathrm{RhD}$ negative erythrocytes (Key Biologics, LLC, Memphis, TN, USA) as previously described for the production of the clinical-grade cell banks [31]. For two participants in group B (P7 and P8), the Pf 7G8 cell bank was expanded in erythrocytes derived from the blood of the study participant. Parasite cultures were checked regularly, at which time, thin blood films were made from collected samples, stained with Diff Quik (Bacto Laboratories) and read to ascertain the parasitemia. As required, the parasites were sub-cultured using freshly washed human erythrocytes. This culturing process was continued with the number of tissue culture dishes/flasks increasing until the malaria parasite was at ring-stage, and it was calculated that there were sufficient parasite numbers to manufacture the chemically treated pRBC.

\section{Chemical treatment of Pf 7G8 with tafuramycin-A}

The $2 \mathrm{mM}$ TF-A stock solution was prepared according to published methods [18], and aliquots were stored at $-80{ }^{\circ} \mathrm{C}$. Fresh working stocks of $20 \mu \mathrm{M}$ were made from this as required, and serial dilutions were performed in Roswell Park Memorial Institute (RPMI)-1640 (Gibco, Invitrogen Corporation, $\mathrm{CA}$ ) to obtain the appropriate concentration of TF-A for the chemical treatment of pRBCs. Pf $7 G 8$ cultures were centrifuged at $433 g$ for $10 \mathrm{~min}$, and the supernatant removed. The cell pellets were combined in a single tube, and a thin blood smear was prepared to determine parasitemia. The parasitemia of cultures for preparation of chemically treated pRBC was $3-5 \%$. For each vented flask required, $500 \mu \mathrm{l}$ of packed cells (pRBCs and uninfected red blood cells [uRBCs]) was added to $9 \mathrm{ml}$ of pre-warmed RPMI-1640 medium. One millilitre of the appropriate TF-A solution was added to obtain a final concentration of either $50 \mathrm{nM}$ (group A) or $200 \mathrm{nM}$ of TF-A (group B). This cell suspension was incubated for $40 \mathrm{~min}$ in a $37{ }^{\circ} \mathrm{C}$ incubator with $5 \% \mathrm{O}_{2}, 5 \% \mathrm{CO}_{2}$, and $90 \% \mathrm{~N}_{2}$, and the flasks were gently agitated every $10 \mathrm{~min}$. The packed cells were transferred to $50 \mathrm{ml}$ conical tubes and washed with RPMI-1640 at $433 g$ for $5 \mathrm{~min}$, and the supernatant discarded. The pellet was resuspended in RPMI-1640 and incubated at $37^{\circ} \mathrm{C}$ for a further $20 \mathrm{~min}$. The pRBC were washed twice more with RPMI-1640 and a final wash in $0.9 \%$ saline for injection. Finally, the pellet was re-suspended in saline for injection and a cell count was performed to calculate the volume required for the immunising dose. This was re-suspended in saline for injection to give a final volume of $2 \mathrm{ml} /$ dose.

\section{Preparation and administration of the chemically treated Pf vaccine}

The vaccine was dispensed into as many $2 \mathrm{ml}$ syringes as required for administration to the study participants who were inoculated by intravenous injection. Study participants received an inoculum containing either $3 \times 10^{7}$ Pf 7 G8 pRBC treated with $50 \mathrm{nM}$ of TF-A (group A) or $3 \times 10^{7}$ Pf 7 G8 $\mathrm{pRBC}$ treated with $200 \mathrm{nM}$ of TF-A (group B). The number of parasites present in each batch of vaccine was verified retrospectively by undertaking qPCR on surplus material.

\section{Evaluation of the chemically treated Pf vaccine}

During preparation of each batch of chemically attenuated inocula, additional inocula were prepared in parallel for testing as described below. 


\section{Sterility testing of the chemically treated Pf vaccine}

Sterility testing of in-process samples and inocula for the assessment of biocontamination with aerobic and anaerobic microorganisms was undertaken by Biotest Laboratories Pty Ltd. (Underwood, Australia) using the direct inoculation technique into tryptone soya broth and thioglycollate medium. Test parameters and acceptance criteria were defined according to the British Pharmacopoeia 2014, Appendix XVI A. Following a 14-day incubation period, there was no evidence of growth of aerobic or anaerobic microorganisms.

\section{Measurement of residual tafuramycin-A in chemically treated vaccine}

A bioanalytical method to determine the residual TF-A in a vaccine dose was developed and qualified by the Centre for Integrated Preclinical Drug Development (CIPDD), Herston, Australia). The range of detection of the assay was $5-200 \mathrm{ng} / \mathrm{ml}$. A vaccine dose from each batch was frozen on dry ice and sent to CIPDD for analysis. During the manufacturing process, the majority of the TF-A is washed away; any residual compound is considered a by-product of manufacture and an impurity in the final product. In all batches produced, the amount of residual TF-A present was well below the limit described in the "European Union (EU) Guidelines on the limits of Genotoxic Impurities" of $1.5 \mu \mathrm{g} /$ person/day (group A: $x=86.04 \mathrm{ng} / \mathrm{vaccine}$ dose; range: $14.4-206.8 \mathrm{ng} / \mathrm{vaccine}$ dose; and group B: $x=114 \mathrm{ng} /$ vaccine dose; range:82.4$136.8 \mathrm{ng} /$ vaccine dose).

\section{Growth of parasites, as assessed by tritiated hypoxanthine uptake}

The viability of the parasites following chemical attenuation was assessed using the $\left[{ }^{3} \mathrm{H}\right]$-hypoxanthine growth inhibition assay. Chemically attenuated ring-stage parasites ( $2 \%$ haematocrit) were added to 96-well flat-bottomed plates $(100 \mu \mathrm{l}$ per well $)$ in quadruplicate. Unattenuated ring-stage parasites and unparasitised red blood cells ( $\mathrm{uRBC}$ ) at $2 \%$ haematocrit were used as positive and background controls respectively. Plates were placed in a $37{ }^{\circ} \mathrm{C}$ incubator with $5 \% \mathrm{O}_{2}, 5 \% \mathrm{CO}_{2}$, and $90 \%$ $\mathrm{N}_{2}$. The assay duration was $48 \mathrm{~h}$ with $\left[{ }^{3} \mathrm{H}\right]$-hypoxanthine $(0.2 \mu \mathrm{Ci} /$ well $)$ added from the start of the experiment. Following incubation, plates were frozen, then subsequently thawed and harvested onto glass fibre mats (Perkin Elmer, Australia) using a Filtermate cell harvester (Perkin Elmer). Radioactivity was measured using a Microbeta $^{2}$ counter (Perkin Elmer). The remainder of the packed cells from the vaccine were placed in culture, and after 1 week, 2 weeks and 3 weeks of culture, cells were harvested and evaluated according to incorporation of $\left[{ }^{3} \mathrm{H}\right]$-hypoxanthine. Twice a week, fresh uRBC were added into the cultures and the medium changed. No growth was observed, as measured by lack of $\left[{ }^{3} \mathrm{H}\right]$-hypoxanthine incorporation, compared to unattenuated Pf 7G8 control samples that were cultured in parallel.

\section{PCR}

Sample preparation, DNA extraction and parasitemia, as measured by qPCR, were undertaken as previously described [33] with the following modifications. The standard curve was prepared from a lyophilized World Health Organisation (WHO) Pf international standard (NIBSC code: 04/176) [34] that was reconstituted in $500 \mu \mathrm{l}$ of nuclease-free water and diluted in a 1:1 solution with 1 $\mathrm{X}$ phosphate buffered saline (PBS) (Gibco). DNA was isolated from $500 \mu \mathrm{l}$ of this solution at a concentration of $5 \times 10^{8} \mathrm{IU} / \mathrm{ml}$. Blood samples from study participants and standards were tested in triplicate. Established modified calculations [35] were used to equate international units $(\mathrm{IU}) / \mathrm{ml}$ to parasites $/ \mathrm{ml}$, with $1 \mathrm{IU} / \mathrm{ml}$ equivalent to 0.5 parasites $/ \mathrm{ml}$. The number of parasites/ $\mathrm{ml}$ was calculated using the CFX96 Touch Real Time Detection System software (BioRad, Australia).

\section{Collection and processing of samples from study participants} Whole blood was collected from study participants in sodium heparin tubes and centrifuged at $433 g$ for $10 \mathrm{~min}$. Plasma was removed and stored at $-80{ }^{\circ} \mathrm{C}$ until it was required for analysis. The cell pellet was diluted 1:1 in RPMI-1640, and peripheral blood mononuclear cells (PBMCs) were isolated by density centrifugation with Ficoll-Paque (Amersham). PBMCs were washed, resuspended at $1 \times 10^{7}$ cells $/ \mathrm{ml}$ in $90 \%$ heat inactivated foetal bovine serum (FBS) $/ 10 \%$ dimethyl sulfoxide and frozen to $-80{ }^{\circ} \mathrm{C}$ at $1{ }^{\circ} \mathrm{C} / \mathrm{min}$ in freezing containers for $24 \mathrm{~h}$ (Nalgene), before transfer to liquid $\mathrm{N}_{2}$ for storage.

\section{Enzyme-linked immunosorbent assay (ELISA)}

NUNC Maxi-sorp immunoplates (Thermoscientific, Australia) were coated with $5 \mu \mathrm{g} / \mathrm{ml}$ of crude Pf 7G8 antigen in bicarbonate coating buffer, $\mathrm{pH} 9.6$ and incubated overnight at $4{ }^{\circ} \mathrm{C}$. After washing with $0.05 \%$ Tween20/ PBS, plates were blocked with $10 \%$ skim milk buffer $/ 0.05 \%$ Tween 20/PBS and incubated at $37^{\circ} \mathrm{C}$ for $2 \mathrm{~h}$. Following washing, plasma (diluted 1:50 in 5\% skim milk buffer/ $0.05 \%$ Tween 20/PBS) was added to the plates and they were incubated at $37^{\circ} \mathrm{C}$ for $1 \mathrm{~h}$. The plates were washed again, and a goat anti-human IgG horseradish peroxidase conjugate (Abcam, Australia) or a goat anti-human IgM Fc5 $\mu$ horseradish peroxidase conjugate (Merck Millipore) was added at 1:10,000 (IgG) or 1:2,500 (IgM) in 5\% skim milk buffer/0.05\% Tween 20/PBS and plates were incubated at $37{ }^{\circ} \mathrm{C}$ for $1 \mathrm{~h}$. Following further washing, tetramethylbenzadine (TMB) substrate solution (Becton Dickinson, Australia) was added and plates were incubated at room temperature for 10-15 min. Absorbance 
was measured at $650 \mathrm{nM}$ on an xMark micro-plate reader (Bio-rad, Australia). Positive control serum was obtained from residents of malaria-endemic areas. Negative control serum was obtained from unexposed Brisbane residents.

\section{PBMC stimulation assays}

Upon thawing, cells were washed thrice in complete medium (RPMI-1640 containing 10\% heat inactivated human serum, $2 \mathrm{nM}$ L-glutamine, $100 \mathrm{U} / \mathrm{ml}$ of penicillin and $100 \mathrm{mg} / \mathrm{ml}$ of streptomycin sulphate), re-suspended in complete medium, counted using trypan blue (Sigma) and aliquoted into U-bottom 96-well plates.

For T cell proliferation assays, $2 \times 10^{5}$ cells in $100 \mu \mathrm{l}$ was added per well. Subsequently, $100 \mu \mathrm{l}$ of purified fresh pRBCs at trophozoite/schizont stage (Pf 7G8, Pf NF54 or Plasmodium knowlesi A1H1.1) or uRBCs $\left(6 \times 10^{5}\right.$ cells/ well), 1\% phytohaemagglutinin (PHA; Gibco) or media only was added, and PBMCs were cultured for 7 days at $37{ }^{\circ} \mathrm{C}, 5 \% \mathrm{CO}_{2}$. Each treatment was tested in triplicate.

For intracellular cytokine staining, $5 \times 10^{5}$ cells in $100 \mu \mathrm{l}$ were added per well. Subsequently, $100 \mu \mathrm{l}$ of purified fresh Pf 7 G8 pRBCs or uRBCs $\left(1 \times 10^{6}\right.$ cells/well $), 1 \%$ PHA or media only was added, and PBMCs were cultured for $36 \mathrm{~h}$ at $37{ }^{\circ} \mathrm{C}, 5 \% \mathrm{CO}_{2}$. Each treatment was tested in triplicate. Sorbitol-synchronised, Mycoplasma-negative, live, late-stage trophozoite/schizont stage pRBCs used in the above in vitro assays were purified by magnetic separation over CS columns (Miltenyi Biotec) on a VarioMACs magnet (Miltenyi Biotec) for these assays.

\section{Measurement of PBMC proliferation}

For assessing proliferation of PBMCs via the incorporation of radioisotope, the unlabelled cells were pulsed with $1 \mu \mathrm{Ci}$ of ${ }^{3}[\mathrm{H}]$-thymidine/well (Perkin Elmer, Australia) for the final $18 \mathrm{~h}$ and plates were stored at $80{ }^{\circ} \mathrm{C}$. Following thawing, cells were harvested onto glass fibre mats (Perkin Elmer, Australia) using a Filtermate cell harvester (Perkin Elmer) and radioactivity was measured using a $\beta$-scintillation microplate counter (Perkin Elmer). The uptake of ${ }^{3}[\mathrm{H}]$-thymidine was measured as corrected counts per minute (CCPM), and results were expressed as deltaCPM, which is defined as the ${ }^{3}[\mathrm{H}]$-thymidine $(\mathrm{CPM})$ in the presence of stimulus, subtracting the average ${ }^{3}[\mathrm{H}]$-thymidine (CPM) incorporated in the presence of the appropriate control stimulus (e.g. unparasitised red blood cells).

\section{Detection of cytokines by cytometric bead array}

After 6 days of culture, prior to the addition of radioisotope, cell culture supernatants were removed and frozen at $-80{ }^{\circ} \mathrm{C}$. Cytokines were measured in the thawed culture supernatants using a Th1/Th2/Th17 cytometric bead array (CBA) kit (BD Biosciences) according to the manufacturer's instructions. Samples were analysed on a
CyAn ADP flow-cytometer, and data analysis was performed using BD FCAPArray software. To determine agonist-specific cytokine induction, background levels from $\mathrm{uRBC}$ alone were subtracted. Selected plasma samples were also analysed with Th1/Th2/Th17 CBA kits according to the manufacturer's instructions.

\section{Identification of cellular sources of cytokines by flow cytometry}

For the final $4 \mathrm{~h}$ of incubation, Golgi-Plug (BD Biosciences) was added. Plates were removed from the incubator and centrifuged at $433 g$ for $5 \mathrm{~min}$. To enable dead cell exclusion, the LIVE/DEAD Aqua Fixable Dead Cell Stain (Thermofisher Scientific) was added to the cells according to manufacturer's instructions and incubated in the dark at room temperature for $30 \mathrm{~min}$. Following washing, antibodies for staining of cell surface markers $(\gamma \delta$ TCR PE-CF594, clone B1; CD3 PerCp, clone SK7; CD4 450, clone RPA-T4; CD8 PECy7, clone RPA-T8; CD45RO APC-H7, clone UCHL1; all from BD Biosciences) were diluted in FACs buffer (1\% bovine serum albumin [BSA]/ PBS), added to cells and incubated for $20 \mathrm{~min}$ in the dark on ice. Following washing with FACs buffer, cells were fixed in $40 \% v / v$ formalin at room temperature for $15 \mathrm{~min}$. Cells were fixed and permeabilised using the BD Fix/Perm Kit (BD Biosciences) according to the manufacturer's instructions. Intracellular staining with cytokine-specific antibodies (IFN- $\gamma$ APC, clone B27; TNF FITC, clone 6401.1111; IL-2 PE, clone MQ1-17H12; all from BD Biosciences) and the appropriate isotype controls was performed on ice for $30 \mathrm{~min}$. Following washing, cells were resuspended in FACs buffer for analysis of the Cyan ADP flow cytometer (Beckman Coulter, Australia). Data analysis was performed using FlowJo V10 (FlowJo, LLC).

\section{Statistics}

All data were analysed and graphed using GraphPad PRISM 6. One-way ANOVA was performed on datasets followed by Dunnett's multiple comparisons test. For the antibody and T cell proliferative data, analyses were conducted at an individual level, using assay replicates and comparing responsiveness at day 0 with subsequent time points. For all other immunological analyses, data was combined for all individuals within a group at each time point, and comparisons were conducted between day 0 and subsequent time points.

\section{Results}

\section{Parasite growth in volunteers post-inoculation}

We initially established the minimal dose of TF-A necessary to completely attenuate Pf 7G8 and prevent growth of the parasite in vitro. We observed that a dose of $50 \mathrm{nM}$ was sufficient as demonstrated by the lack of parasite growth measured by ${ }^{3}[\mathrm{H}]$ hypoxanthine 
incorporation (Additional file 1: Figure S1). We then produced vaccine doses for administration to volunteers. The biological properties of the vaccine, including assessment of residual TF-A are described in the "Methods" section.

We treated three study participants in group A $(\mathrm{P} 1 \rightarrow$ P3), with a single vaccine dose containing $3 \times 10^{7} \mathrm{pRBC}$ treated with $50 \mathrm{nM}$ TF-A. The dose of $3 \times 10^{7} \mathrm{pRBC}$ was chosen based on the lowest dose of a $P$. chabaudi-attenuated vaccine shown to be efficacious in mice $\left(10^{4}\right)$ [18], with a correction for approximate weight differences. Surprisingly, all three participants developed a sub-patent Pf infection (Fig. 1a) necessitating initiation of anti-malarial treatment with $\mathrm{A} / \mathrm{L}$ on days 10-13 (according to symptoms and the parasitemia threshold as defined in the study protocol $[11,500$ parasites per millilitre]). As a TF-A concentration of $50 \mathrm{nM}$ was insufficient to completely attenuate the parasite, a higher dose was used to prepare the vaccine for the next study group (group B), which received a single vaccine dose of $3 \times 10^{7}$ pRBC treated with 200 nM TF-A. Apart from a sub-patent parasitemia detected by qPCR on day 2 only, all five participants $(\mathrm{P} 4 \rightarrow \mathrm{P} 8)$ remained parasite-negative until day 28, when drug treatment with $\mathrm{A} / \mathrm{L}$ was initiated in accordance with the study protocol (Fig. 1b).

\section{Adverse events and lab abnormalities}

A number of adverse events (AEs) and abnormal laboratory values considered probably or possibly related to the vaccine were recorded for participants in group $\mathrm{A}$ (Additional file 1: Tables S2 and S3). The majority of these were typical of symptoms or blood abnormalities observed during Pf infection (malaria) and resolved following completion of anti-malarial drug treatment.
There were no AEs attributable to the vaccine recorded for the participants in group $B$.

\section{Induction of alloantibodies}

Blood group $\mathrm{O}$ RhD negative blood was used to manufacture the chemically attenuated $\mathrm{pRBC}$ inoculum for P1 $\rightarrow$ P6. However, we observed that P6 seroconverted to the minor $\mathrm{Rh}$ antigen "c" by day 28. While his $\mathrm{Rh}$ phenotype was "CDe", and the phenotype of the donor red blood cells was "ce", this was an unexpected finding as it had not been observed in any of $>380$ volunteers previously given controlled human blood-stage malaria infections (J McCarthy, pers. comm. and DI Stanisic, unpublished data). As a result of this finding, the inocula for the last two volunteers in group B (P7 and P8) were manufactured using their own blood.

\section{Induction of parasite-specific antibody responses}

Plasma samples from study participants were tested for Pf 7G8-specific IgM and IgG by ELISA. In all participants in group $\mathrm{A}$, the group that developed Pf infection, parasite-specific IgM was induced, with significantly higher levels present on day 28 compared to day $0 \quad(p<0.01$ for $\mathrm{P} 1$ and $\mathrm{P} 3 ; p<0.001$ for $\mathrm{P} 2)$ (Fig. 2a). Levels of parasite-specific IgM in group $B$ (Fig. 2b), the group that did not develop Pf infection, and IgG in groups A (Additional file 1: Figure S2A) and B (Additional file 1: Figure S2B) were not significantly elevated compared to day 0 during the course of the study $(p>0.05)$.

\section{Induction of parasite-specific cellular responses}

To assess cellular responses, parasite-specific lymphoproliferation (as measured by ${ }^{3}[\mathrm{H}]$-thymidine incorporation)
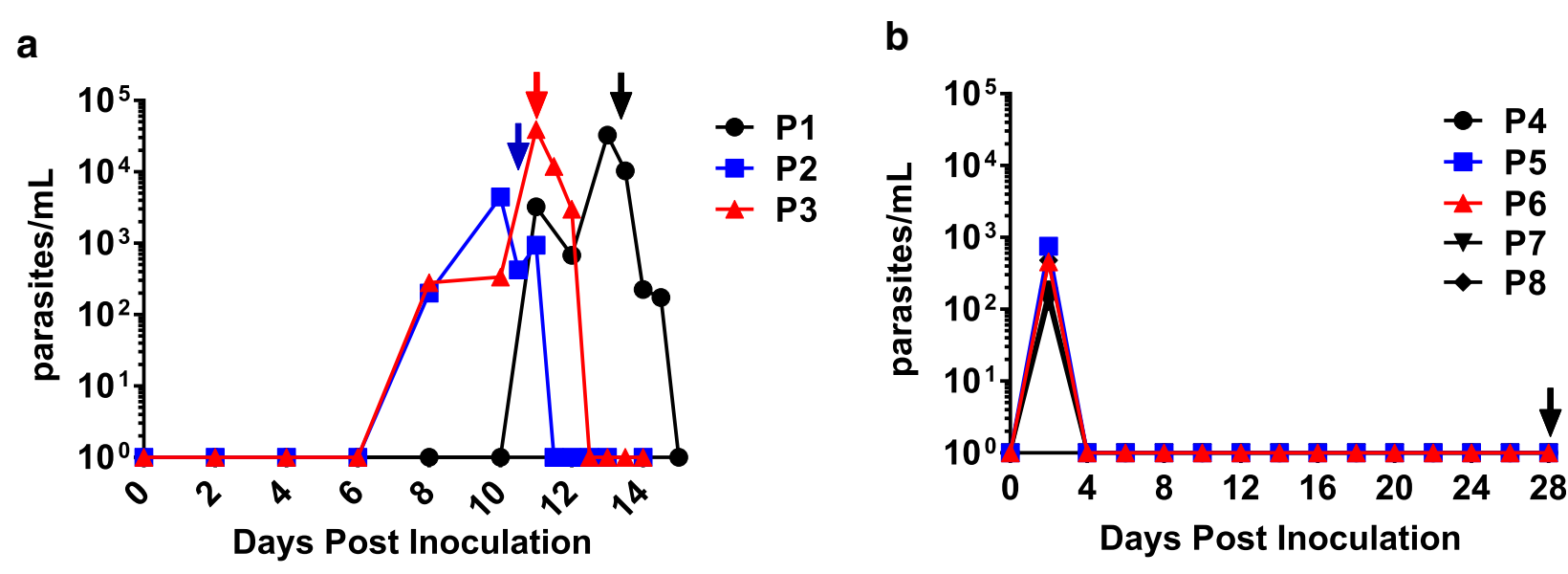

Fig. 1 The course of parasitemia in study participants inoculated with chemically treated P. falciparum 7G8. Parasite levels in study participants, as determined by $\mathrm{qPCR}$, following inoculation with $\mathbf{a} 3 \times 10^{7} \mathrm{P}$. falciparum $\mathrm{pRBC}$ treated with $50 \mathrm{nM}$ tafuramycin-A (TF-A) or $\mathbf{b} 3 \times 10^{7} \mathrm{P}$. falciparum PRBC treated with 200 nM TF-A. Arrows indicate initiation of drug treatment with artemether-lumefantrine 


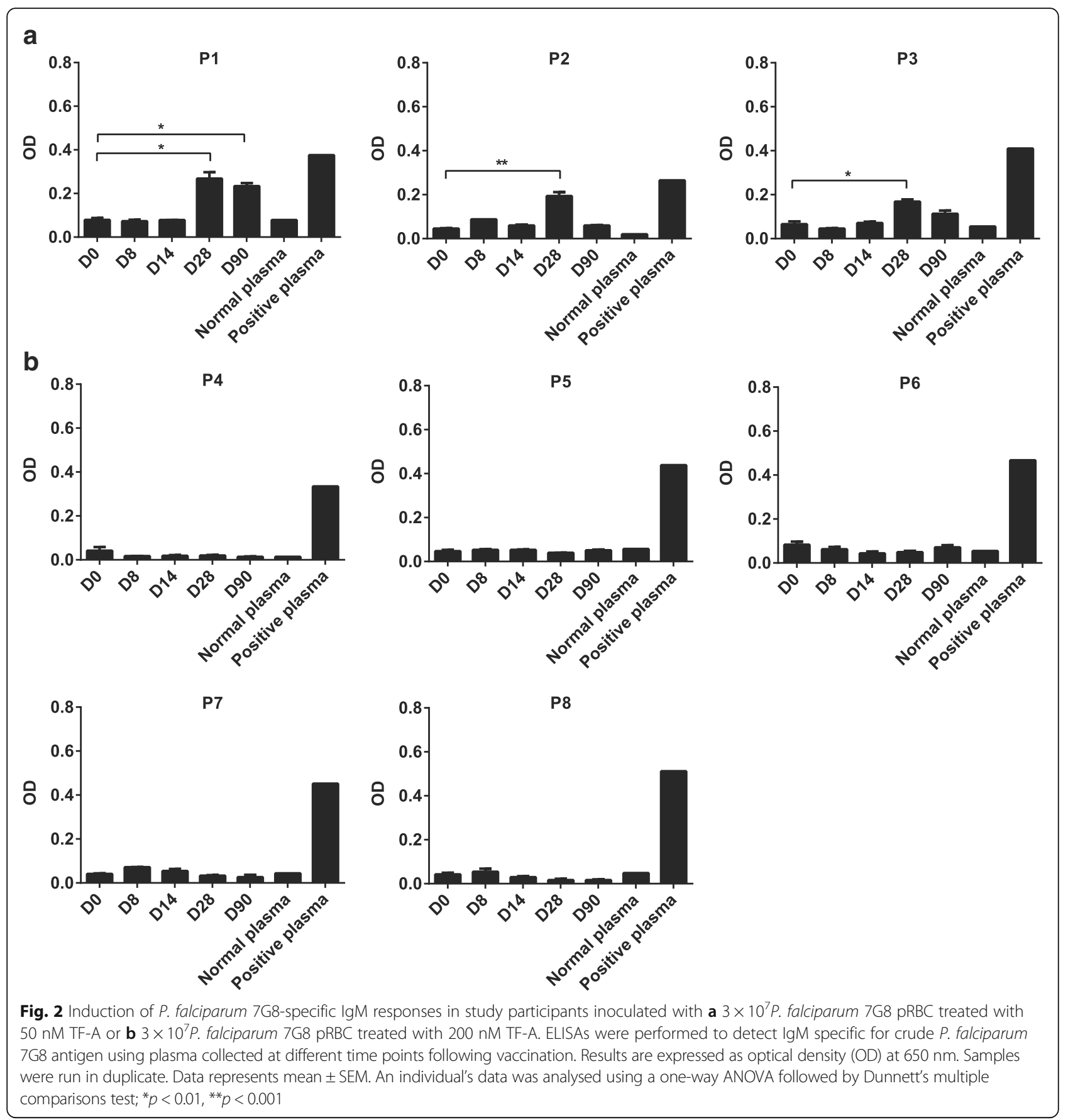

was assessed to homologous (7G8) and heterologous (PfNF54 and P. knowlesi) pRBC. In group A, responses to homologous parasites (7G8) did not increase significantly compared to day $0(p>0.05)$ (Fig. 3a). There was a decrease in responses between days $8-13$, which was associated with the development of infection and the administration of anti-malarial treatment (Fig. 1). Proliferative responses to the heterologous parasites did not increase at any time point for P1 $(p>0.05)$ (Fig. 3a). For P2 and P3, significantly increased responses compared to day
0 were seen to PfNF54 and P. knowlesi at various time points $(p<0.05)$ (Fig. 3a).

In group $\mathrm{B}$, proliferative responses to homologous parasites (Fig. 3b) were significantly increased at one or more time points compared to day 0 for all five individuals $(p<0.04$ for all); for $3 / 5$ individuals, this was observed at three or more time points. Additionally, for 3/ 5 individuals, this was observed at D90. For heterologous parasites, significantly increased responses were seen to PfNF54 at one of more time points in all participants 


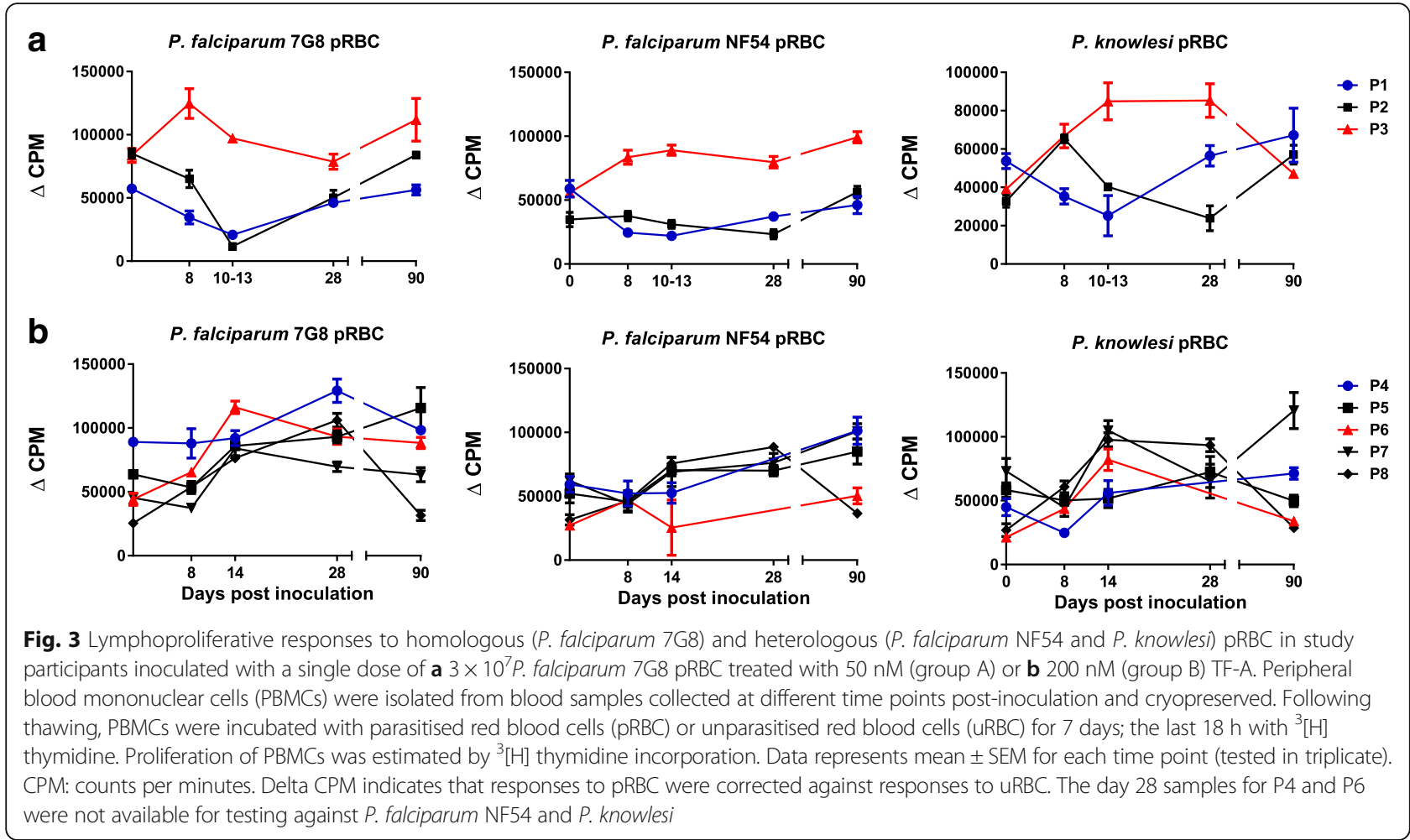

$(p \leq 0.02$ for all) and to $P$. knowlesi in $4 / 5$ study participants (P4, P6, P7 and P8) ( $p<0.05$ for all) (Fig. 3b).

Cytokines present in the supernatants of the PBMC cultures in the 7-day assay following incubation with $P$. falciparum 7G8 pRBC were measured. Similar to the lymphoproliferative responses, for group $\mathrm{A}$, the production of IFN- $\gamma$, TNF and IL- 6 generally decreased compared to day 0 between days $8-13$; in most instances, this returned to baseline levels by D90 (Fig. 4a and Additional file 1: Figure S3A). IL-4 and IL-10 levels increased in all individuals in parallel with the decrease in inflammatory cytokines. When combining data for all individuals in group A at each time point, there was a significant increase in IL-10 production at day $14(p=0.018)$ compared to day 0 . Production of IL-2 and IL-17A was not consistent between individuals (Additional file 1: Figure S3A). In group B, an increase in IFN- $\gamma$, TNF and IL-10 production compared to day 0 was observed for all individuals (Fig. 4b). When combining data for all individuals in group B at each time point, for IFN- $\gamma$, this increase was significant at days 14 and 28 ( $p<0.02$ for both), and for IL-10, it was significant at day $14 \quad(p=0.043)$. Production of IL-2, IL-4, IL-6 and IL-17A varied over time and between individuals (Fig. 4b and Additional file 1: Figure S3B).

We were interested in the endurance of the altered immune response following vaccination. Four of the five individuals in group B demonstrated persisting altered immune responses, compared to day 0 , to $P$. falciparum
7 G8 pRBC resulting in production of the parasiticidal cytokine, IFN- $\gamma$, at day 90 and two of these individuals also had persisting TNF responses (Fig. 4b). The one individual (P4) whose response did not persist to day 90 was responsive until day 28 .

Due to the appearance of clinical symptoms in participants in group A, we evaluated plasma levels of key inflammatory and anti-inflammatory cytokines in these individuals and compared these levels with those in plasma from participants in a previous study where we had evaluated the infectivity of the Pf 7G8 cell bank [32]. Similar parasitemias were observed in those study participants [32], who were asymptomatic at the time of initiation of $\mathrm{A} / \mathrm{L}$ treatment and in whom it was initiated according to the same criteria for reaching the parasitemia threshold. Overall, higher levels of IL- 6 and IL-10 were observed in individuals in the current study compared with the previous infectivity study (Additional file 1: Figure S4).

The intracellular production of IFN- $\gamma$, TNF and IL-2 in response to homologous $\mathrm{pRBC}$ in short-term in vitro assays was also examined in $\mathrm{CD}^{+}{ }^{+} \mathrm{T}$ cells. Initially, we examined $\mathrm{CD}^{+} \mathrm{T}$ cells to identify monofunctional and polyfunctional $\mathrm{T}$ cells secreting the parasiticidal cytokines, IFN- $\gamma$ and TNF. T cells secreting these cytokines individually or in combination were induced in both groups following inoculation (Fig. 5 and Additional file 1: Figure S5). In group B, T cells secreting IFN- $\gamma$ alone or in combination with TNF were the most frequently detected (Fig. 5). When combining data for all individuals 


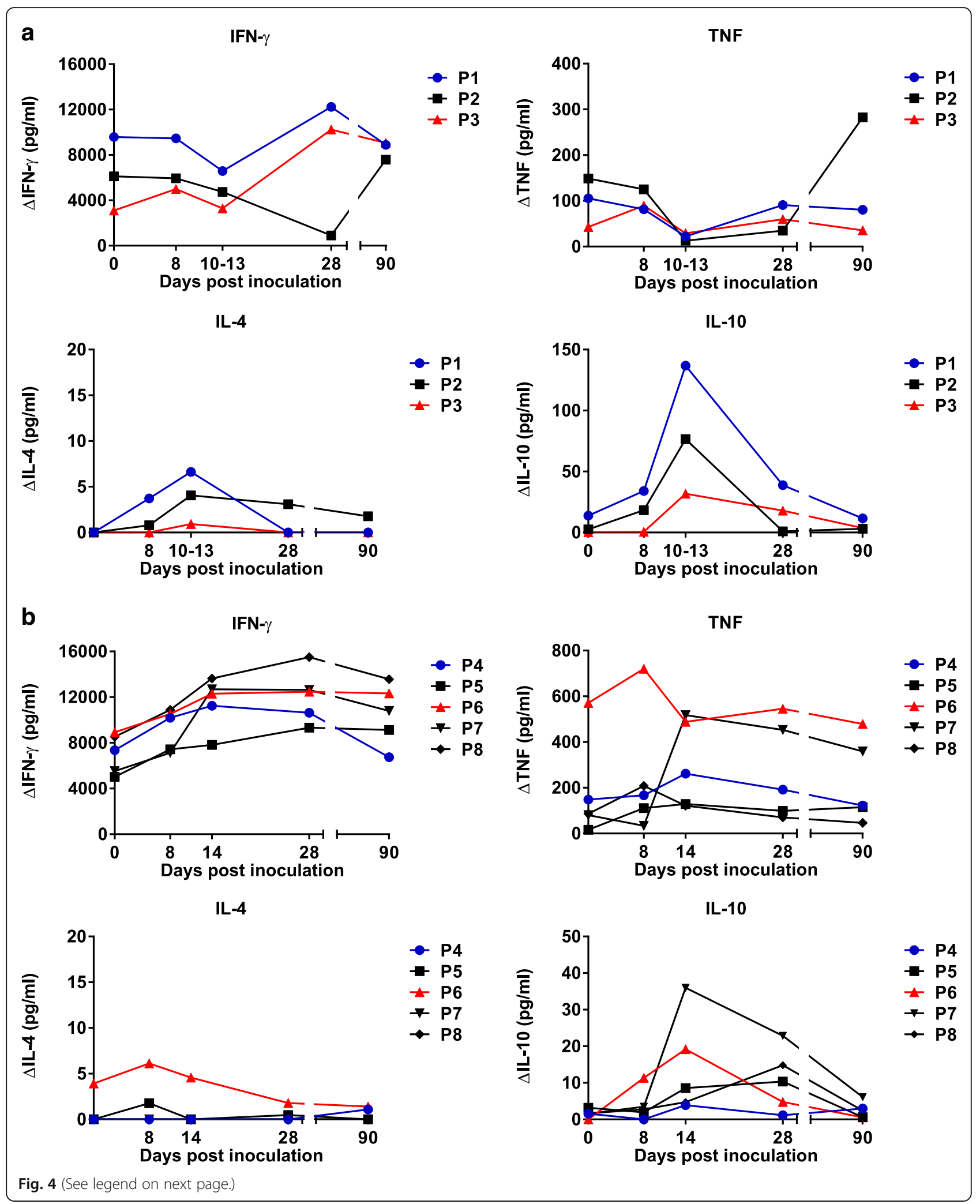


(See figure on previous page.)

Fig. 4 Cytokine responses to P. falciparum 7G8 in study participants inoculated with a single dose of a $3 \times 10^{7} P$. falciparum 7G8 pRBC treated with $50 \mathrm{nM}$ (group A) or b $200 \mathrm{nM}$ (group B) TF-A. Peripheral blood mononuclear cells (PBMCs) were isolated from blood samples collected at different time points post-inoculation and cryopreserved. Following thawing, PBMCs were incubated with parasitised red blood cells (pRBC) or unparasitised red blood cells (URBC) for 7 days. Eighteen hours before the end of the culture period, culture supernatants were collected, pooled $(n=3)$ and used in cytokine bead arrays to quantify the level of cytokines produced in response to $P$. falciparum $7 \mathrm{G} 8$ pRBCs by flow cytometric analysis. Delta cytokine indicates that responses to PRBC were corrected against responses to URBC

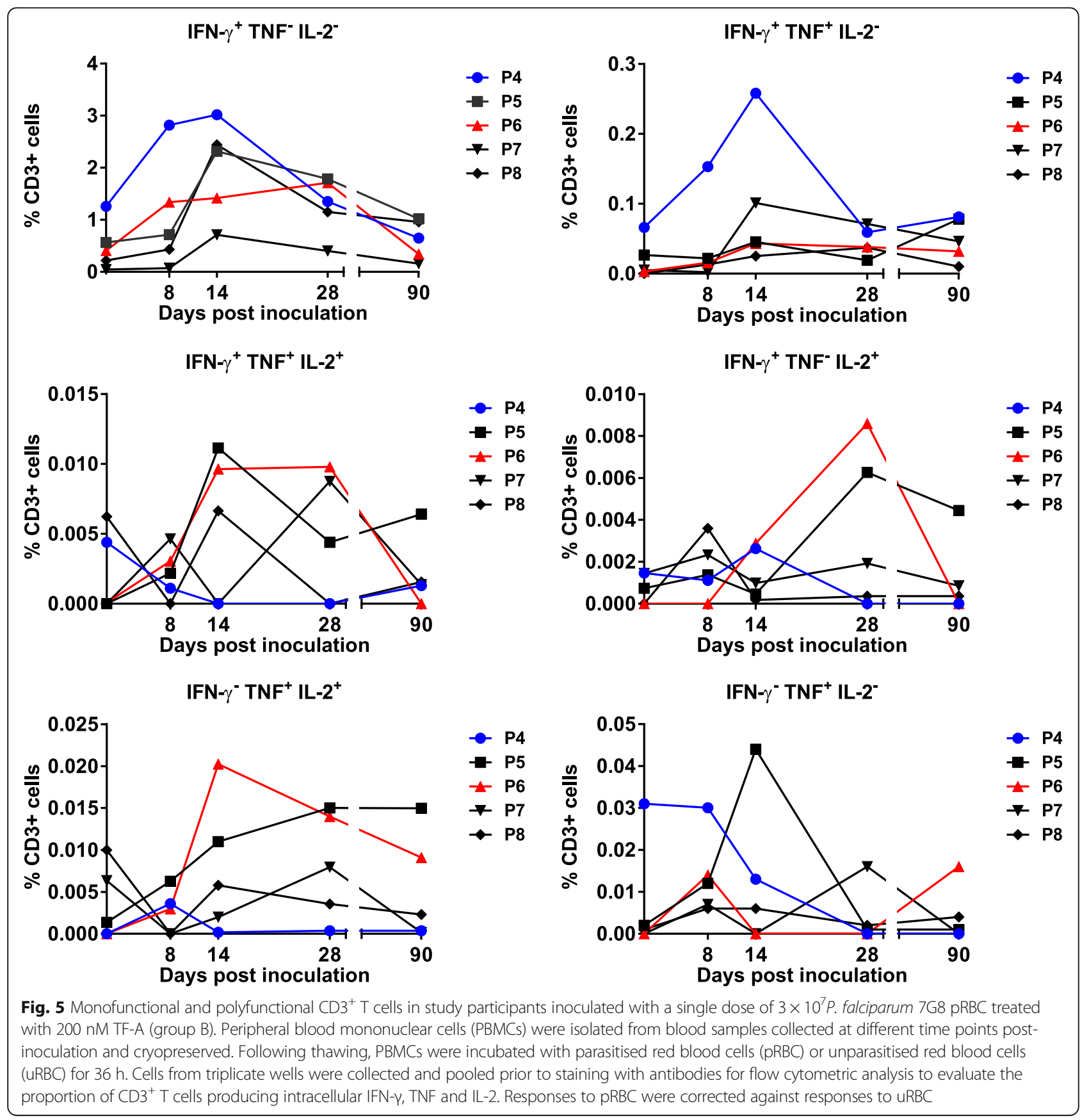


in group B at each time point, there was a significant increase in cells secreting IFN- $\gamma$ alone (i.e. IFN- $\left.\gamma^{+} \mathrm{TNF}^{-} \mathrm{IL}^{-} 2^{-}\right)$when comparing day 14 with day 0 $(p<0.02)$. Triple cytokine-secreting cells (IFN- $\gamma$, TNF and IL-2) were also detected, albeit at lower frequencies.

Intracellular production of the three cytokines in response to homologous $\mathrm{pRBC}$ was then examined individually in naïve $\left(\mathrm{CD}^{+} \mathrm{CD} 45 \mathrm{RO}^{-}\right)$and memory $\left(\mathrm{CD}^{+} \mathrm{CD}^{2} 5 \mathrm{RO}^{+}\right) \mathrm{T}$ cell populations. In both groups, all three cytokines were produced by both cell types with the cellular source and cytokine profile varying between individuals (Fig. 6 and Additional file 1: Figure S6). Importantly, memory $\mathrm{T}$ cells $\left(\mathrm{CD}^{+} \mathrm{CD} 45 \mathrm{RO}^{+}\right)$producing the three cytokines were induced following inoculation in all individuals in group B following inoculation (Fig. 6). When combining data for all individuals in group $\mathrm{B}$ at each time point, $\mathrm{CD}^{+}{ }^{+} \mathrm{CD} 45 \mathrm{RO}^{+}$cells secreting IFN- $\gamma$ were significantly increased at day 14 compared with day $0(p=0.04)$.

Intracellular cytokine production was also examined according to $\mathrm{CD}^{+} \mathrm{T}$ cell subset: helper $\mathrm{T}$ cells $\left(\mathrm{CD}^{+} \mathrm{CD}^{+}{ }^{+} \mathrm{CD} 8^{-}\right)$; cytotoxic $\mathrm{T}$ cells $\left(\mathrm{CD}^{+} \mathrm{CD}^{-} \mathrm{CD}^{+}\right)$; and $\gamma \delta \mathrm{T}$ cell $\left(\mathrm{CD} 3^{+} \gamma \delta^{+}\right)$populations. There was heterogeneity in the cellular source and cytokine profile in individuals across both groups A and B (Fig. 7 and Additional file 1: Figure S7). Generally, in group B, with the exception of TNF production in $\mathrm{CD}^{+} \mathrm{T}$ cells, IFN- $\gamma$ and TNF production by the different $\mathrm{T}$ cell subsets increased following inoculation and peaked on day 14 (Fig. 7). In this group, $\gamma \delta \mathrm{T}$ cells were the $\mathrm{T}$ cell subset with the highest proportion of cells producing IFN $-\gamma$, TNF or IL-2. When combining data for all individuals in group $\mathrm{B}$ at each time point, and comparing responses to day $0, \mathrm{CD}^{+} \mathrm{T}$ cells producing IFN- $\gamma$ were significantly increased at day $14(p=0.007)$ and $C D 4^{+} \mathrm{T}$ cells and $\gamma \delta$ $\mathrm{T}$ cells secreting TNF were also significantly increased at day 14 ( $p=0.040$ and 0.036 respectively).

\section{Discussion}

Here, for the first time, we describe the preparation and administration to humans of chemically treated Pf pRBC and show that a single dose of attenuated Pf pRBC is able to induce strain and species-transcending cellular immune responses in malaria-naïve individuals. Pf-specific antibody responses were not detected. The dose-ranging component of this study indicates that doses of > $50 \mathrm{nM}$ TF-A must be used in vitro to effectively attenuate $P$. falciparum and prevent the development of the clinical manifestations of Pf infection in vivo.

Lymphoproliferative responses were examined, and as previously shown, all individuals had pre-existing responses to $\mathrm{pRBC}$ at baseline [36], despite no previous exposure to $\mathrm{Pf}$. This responsiveness could be due to cross-reactivity between parasite antigens and environmental organisms [36]. Critically, the responses to homologous pRBC increased following inoculation in individuals who received completely attenuated chemically treated Pf 7G8 (group B), and they persisted in a proportion of individuals for up to 90 days (the duration of the study). Proliferative responses to heterologous parasites were also observed in more than half of these individuals. It is possible that administration of additional doses of attenuated parasites will augment the breadth, magnitude and persistence of this response. Cytokine production in response to homologous parasites was also examined, and increased production of IFN- $\gamma$ and TNF (as measured in culture supernatants) was observed following inoculation. Both IFN- $\gamma$ and TNF are strongly implicated in protection against Pf infection [25-28, 37], and the latter also in pathology [38-40]. Increased levels of IL-10 were also observed; it is a regulatory cytokine thought to play a crucial role in Plasmodium spp. infection, due to its ability to regulate both innate and adaptive inflammatory responses, e.g. production of TNF (reviewed in [41]).

By using intracellular cytokine staining, we further examined production of IFN- $\gamma$, TNF and IL- 2 by $\mathrm{CD}^{+}{ }^{+} \mathrm{T}$ cells. In group $\mathrm{B}, \mathrm{T}$ cells secreting IFN- $\gamma$ alone or in combination with TNF were the most frequently detected; however, a significant increase following vaccination was only seen at day 14 for $\mathrm{CD}^{+} \mathrm{T}$ cells secreting IFN- $\gamma$ alone. Previous studies on malaria and other infectious diseases have demonstrated a correlation between the presence of antigen-specific polyfunctional $\mathrm{T}$ cells and protective immunity induced following vaccination (e.g. [42-44]). Although the prevalence of these cells was low and the increases in these populations following vaccination were not significant, administration of additional vaccine doses may increase their prevalence and longevity. Future studies examining the protective efficacy of a chemically attenuated whole blood-stage parasite vaccine should examine the role of these polyfunctional $\mathrm{T}$ cells in protection. Importantly, we also observed the induction of cytokine-secreting memory $\mathrm{T}$ cells $\left(\mathrm{CD}^{+}{ }^{+} \mathrm{CD} 45 \mathrm{RO}^{+}\right)$following inoculation. It would be of interest in future studies to undertake additional phenotyping to examine the pluripotency of this memory $\mathrm{T}$ cell population. Analysis of the $\mathrm{CD}^{+} \mathrm{T}$ cell subsets following inoculation showed that there was a significant increase at day 14 in $\mathrm{CD}^{+}$and $\gamma \delta \mathrm{T}$ cells producing TNF and in $\mathrm{CD}^{+} \mathrm{T}$ cells producing IFN- $\gamma$.

Pf-specific IgM was detected only in individuals who developed an active malaria infection (group A). The lack of antibody production in group B may be a function of antigen dose, as they were exposed to a lower dose of parasites. It is possible that with administration of further doses of the completely attenuated parasites, an antibody response may be induced.

In a previous clinical study investigating the protective efficacy of multiple low-dose Pf infections 


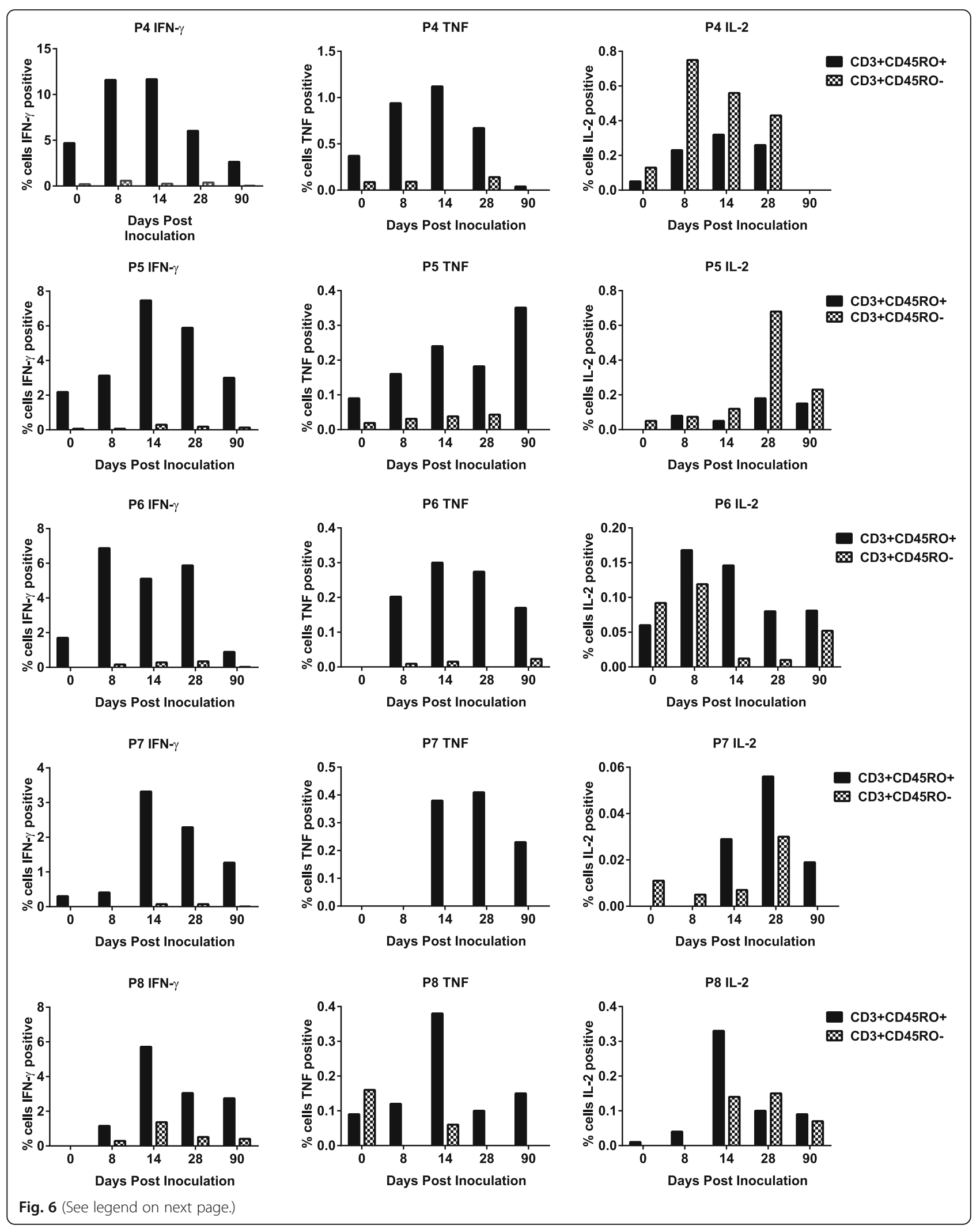


(See figure on previous page.)

Fig. 6 Cytokine production in naïve and memory T lymphocytes in study participants inoculated with a single dose of $3 \times 10^{7} P$. falciparum $7 \mathrm{G} 8$ pRBC treated with 200 nM TF-A (group B). Peripheral blood mononuclear cells (PBMCs) were isolated from blood samples collected at different time points post-inoculation and cryopreserved. Following thawing, PBMCs were incubated with parasitised red blood cells (pRBC) or unparasitised red blood cells (URBC) for $36 \mathrm{~h}$. Cells from triplicate wells were collected and pooled prior to staining with antibodies for flow cytometric analysis to evaluate the proportion of naive $T$ cells $\left(\mathrm{CD}^{+} \mathrm{CD}^{+} 5 \mathrm{RO}^{-}\right)$and memory $\mathrm{T}$ cells $\left(\mathrm{CD} 3^{+} \mathrm{CD} 45 \mathrm{RO} \mathrm{O}^{+}\right)$producing intracellular IFN- $\mathrm{y}_{\text {, TNF }}$ and IL-2. Responses to pRBC were corrected against responses to URBC

attenuated in vivo with atovaquone/proguanil, we observed protection against homologous challenge in three out of four volunteers [29]. However, we could not exclude that protection was due in part to residual drug [45]. Pf-specific cellular immune responses were induced in the absence of Pf-specific antibody in that study, similarly to what we observed in the current study. However, the requirement for delayed anti-malarial drug administration is problematic for the feasibility of this in vivo treatment approach as a vaccine strategy. Our current approach of in vitro treatment of $\mathrm{pRBC}$ prior to administration offers a viable alternative.

Induction of parasite-specific cellular immune responses, in the absence of antibodies, was observed in previous rodent studies evaluating the protective efficacy of chemically attenuated $P$. chabaudi pRBC [18]. This is similar to what we observed in the current study, and it differs from the $P$. yoelii $17 \mathrm{X}$ rodent studies, where parasite-specific antibodies were also induced in addition to the cellular immune responses [19]. A further study involving administration of chemically treated Pf FVO

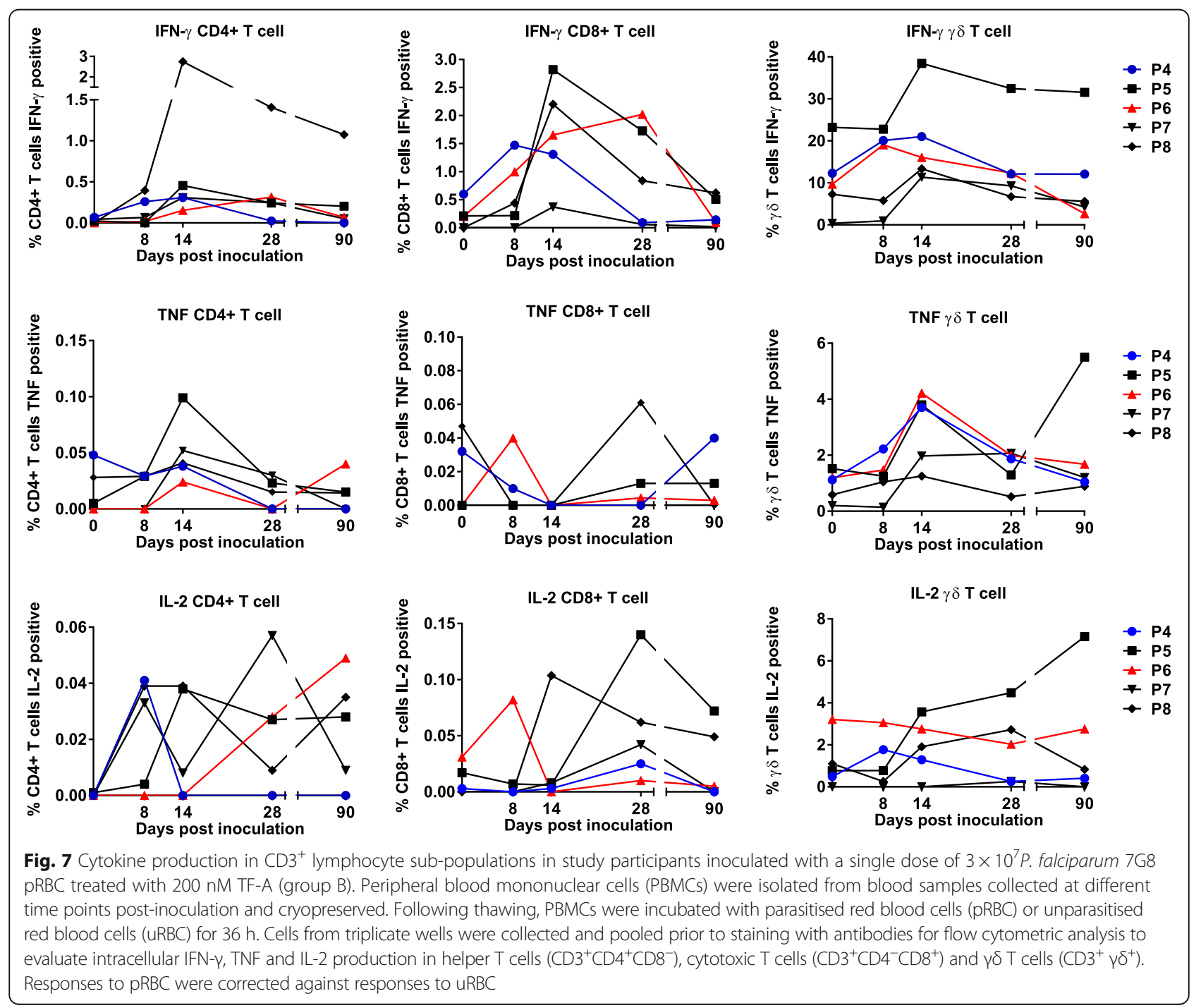


parasites to non-splenectomised Aotus monkeys demonstrated induction of Pf-specific cellular responses in the absence of IgG [30]. Following a single dose of chemically treated parasites, the vaccinated monkeys received a homologous blood-stage challenge with all developing parasitemia and requiring anti-malarial drug treatment. This suggests that more than one vaccine dose may be required for clinical protection.

Rodent studies investigating chemically attenuated Plasmodium spp. suggest that persistence of low levels of parasite antigen may be important for inducing an antibody-independent protective immune response [20]. Although persisting parasites could not be detected in this current study beyond day 2 post-inoculation, it is possible that they were persisting at levels below the limit of detection of the qPCR.

The development and clinical evaluation of this whole parasite asexual blood-stage vaccine approach presented a number of general and specific issues for consideration. The use of human red blood cells in the manufacturing process and the final vaccine product entailed specific regulatory and safety considerations, specifically the possibility of contamination with infectious adventitious agents and allo-immunisation. To address the first issue, we used transfusion-compatible blood products, with collection and screening undertaken according to current regulatory guidelines, and used a defined malaria parasite cell bank grown at Good Manufacturing Practices (GMP) standard that had also been rigorously screened according to regulatory guidelines [31]. Furthermore, the manufacturing process complied with current, local GMP requirements. The second issue, the possibility of allo-immunisation (the induction of antibodies against red blood cell antigens), was addressed by the use of blood from a group $\mathrm{O} \mathrm{RhD}$ negative donor to manufacture the inoculum for group $\mathrm{A}$ and the first three participants in group B (P4-P6). In one study participant, P6, seroconversion to the minor Rh antigen "c" was observed following inoculation. As the Rh phenotype of the donor red blood cells that were used to manufacture the inoculum for the first three participants in group B were "ce" while P6's phenotype was "CDe", it is likely that the induction of "c" antibodies may have been due to injection with the chemically treated pRBC. Seroconversion was not observed in P1-P5 despite incompatibility with the donor red blood cells at the minor $\mathrm{Rh}$ antigens. Although it is not feasible to match donor blood with recipients at all of the minor Rh antigens, following this observation, the inocula for P7 and P8 were manufactured individually using their own red blood cells. In this current study, the inocula were prepared from cultures with a 5\% parasitemia; thus, the total number of red blood cells being injected was 20-fold higher than the number of $\mathrm{pRBC}$. To progress this vaccine strategy and to address the possible induction of alloantibodies, we believe it is critical to reduce the number of red blood cells in the inocula, which could be achieved by purifying the pRBC away from the uninfected red blood cells. This current study involved the administration of only a single dose of Pf pRBC; the impact of multiple doses of Pf pRBC on the induction of alloantibodies is being examined in ongoing studies.

TF-A is a compound with genotoxic potential, and while the majority is washed away during the manufacturing process, its use required the measurement of residual TF-A in an inoculum dose for each manufactured batch. According to the "EU Guidelines on the limits of Genotoxic Impurities" (which has been adopted by our local regulatory body, the Therapeutic Goods Administration), a value of $1.5 \mu \mathrm{g} /$ day of genotoxic impurity is considered to be associated with acceptable risk. Notably, the US FDA stipulates a much higher threshold of $120 \mu \mathrm{g} / \mathrm{day}$, and this is for up to 14 days of continuous administration. The amount of residual TF-A in our inoculum batches was considerably lower than both of these thresholds (group A: $x=86.04 \mathrm{ng} /$ vaccine dose; group $\mathrm{B}: x=114 \mathrm{ng} / \mathrm{vaccine}$ dose). Purification of $\mathrm{pRBC}$ away from $\mathrm{URBC}$ would result in an even further reduction in the amount of residual TF-A.

\section{Conclusions}

This study represents the first clinical evaluation of chemically attenuated whole blood-stage parasites in malaria-naïve human volunteers. When the Pf parasites were completely attenuated, the inoculum was safe and well tolerated, although future studies may need to focus on the purification of pRBC (e.g. magnet purification of trophozoite-stage $\mathrm{pRBC}$ ) for the inoculum to address the possibility of induction of alloantibodies. The induction of strain and species-transcending parasite-specific cellular immune responses following inoculation provides support for the whole blood-stage parasite approach as a means of increasing the breadth of the resulting immune response. While homologous and heterologous protection has been demonstrated in rodent models of malaria $[18,19]$, it is not known whether these cross-reactive immune responses will be protective in humans. These data support further clinical development of chemically attenuated whole blood-stage parasites as a vaccine strategy. Future studies will focus on a multi-dose immunisation regimen and will address whether lower doses of attenuated parasites are immunogenic.

\section{Additional file}

Additional file 1: Table S1. Demographics of study participants. Table S2. Adverse events reported in study participants in group A. Table S3. Abnormal laboratory values reported in study participants in group A. 
Figure S1. In vitro growth of $P$. falciparum 7G8 following treatment with different doses of tafuramycin-A. Figure $\mathbf{S 2}$. Induction of $P$. falciparum $7 \mathrm{G} 8 \mathrm{lgG}$ responses in study participants inoculated with a single dose of (A) $3 \times 10^{7} \mathrm{P}$. falciparum $7 \mathrm{G} 8 \mathrm{pRBC}$ treated with $50 \mathrm{nM}$ of TF-A or (B) $3 \times 10^{7} \mathrm{P}$. falciparum $7 \mathrm{G} 8 \mathrm{pRBC}$ treated with $200 \mathrm{nM}$ of TF-A. Figure S3. Cytokine responses to $P$. falciparum $7 G 8$ in study participants inoculated with a single dose of (A) $3 \times 10^{7} \mathrm{P}$. falciparum $7 \mathrm{G} 8 \mathrm{pRBC}$ treated with $50 \mathrm{nM}$ (group A) or (B) $200 \mathrm{nM}$ (group B) TF-A. Figure S4. Serum cytokine responses in study participants inoculated with a single dose of (A) $3 \times 10^{7} \mathrm{P}$. falciparum 7G8 pRBC treated with 50 nM TF-A (group A) or (B) 1,800 P. falciparum $7 \mathrm{G} 8 \mathrm{pRBC}$ (infectivity study) untreated. Figure S5. Monofunctional and polyfunctional $\mathrm{CD}^{+} \mathrm{T}$ cells in study participants inoculated with a single dose of $3 \times 10^{7} P$. falciparum $7 \mathrm{G} 8 \mathrm{pRBC}$ treated with 50 nM TF-A (group A). Figure S6. Cytokine production in naïve and memory $T$ lymphocytes in study participants inoculated with a single dose of $3 \times 10^{7} \mathrm{P}$. falciparum $7 \mathrm{G} 8 \mathrm{pRBC}$ treated with $50 \mathrm{nM}$ TF-A (group A). Figure S7. Cytokine production in $\mathrm{CD}^{+}$lymphocyte sub-populations in study participants inoculated with a single dose of $3 \times 10^{7}$ P. falciparum $7 \mathrm{G} 8 \mathrm{pRBC}$ treated with $50 \mathrm{nM}$ TF-A (group A). (PDF $675 \mathrm{~kb})$

\section{Abbreviations}

A/L: Artemether-lumefantrine; BSA: Bovine serum albumin; CBA: Cytometric bead array; CCPM: Corrected counts per minute; CIPDD: Centre for Integrated Preclinical Drug Development; CM: Centanamycin; CPM: Counts per minute; ELISA: Enzyme-linked immunosorbent assay; EU: European Union; FBS: Foetal bovine serum; GMP: Good Manufacturing Practices; IFN: Interferon; IgG: Immunoglobulin G; IgM: Immunoglobulin M; IL: Interleukin; IU: International units; ng: Nanogram; nM: Nanomolar; PBMC: Peripheral blood mononuclear cells; PBS: Phosphate buffered saline; Pf: Plasmodium falciparum; PHA: Phytohaemagglutinin; PIC/S: Pharmaceutical Inspection Co-operation Scheme; pRBC: Parasitized red blood cells; qPCR: Quantitative polymerase chain reaction; RPMI: Roswell Park Memorial Institute medium; TF-A: Tafuramycin A; TMB: Tetramethylbenzadine; TNF: Tumour necrosis factor; U: Units; uRBC: Uninfected red blood cells

\section{Acknowledgements}

The authors gratefully acknowledge the study participants. We thank Tanya Forbes and Nicola Cocroft for regulatory support and Dr. Michael Batzloff and Dr. Chris Davis for advice and support throughout the study. We thank Ms. Maryna Brown for assistance with Project Management. We thank Dr. Peter Crompton for kindly providing plasma samples for positive controls for the ELISAs. We would like to thank Professor Dennis Shanks and Dr. Qin Cheng (Australian Army Malaria Institute) for kindly providing the P. falciparum $7 \mathrm{G} 8$ from which the $P$. falciparum $7 \mathrm{G} 8$ cell bank was derived. We would also like to thank Professor Shanks and Dr. Paul Griffin for serving on the Safety Review Team. We thank Dr. Stephanie Yanow for critically reviewing the manuscript.

\section{Funding}

Funding was provided by The Merchant Foundation, Atlantic Philanthropies and the National Health and Medical Research Council (NHMRC) of Australia (program grant to MFG, research fellowship to MFG). The funders had no role in the study design, data collection or analysis, decision to publish or preparation of manuscript.

\section{Availability of data and materials}

The data sets used and/or analysed during the current study are available from the corresponding authors on reasonable request.

\section{Authors' contributions}

DS planned and conducted the experiments, analysed/interpreted the data, managed the clinical study, manufactured the chemically treated inoculum and wrote the manuscript. JF, JM, SC, LG and JG were responsible for the clinical monitoring and management of the study participants. XL manufactured the chemically treated inoculum and assisted with laboratory sample processing and parasite culture for laboratory assays. IED manufactured the TF-A. IR, JP, NW, $\mathrm{SD}$ and $\mathrm{MH}$ assisted in the laboratory monitoring of study participants. SH supplied the $P$. falciparum NF54 parasite line used in the immunogenicity assays and provided regulatory and technical advice for the GMP-compliant production of the cell bank that was used to manufacture the vaccine. MG planned the experiments, contributed to the interpretation of the data and writing of the manuscript. All authors approved the final manuscript.

\section{Ethics approval and consent to participate}

The study protocol was approved by the Griffith University Human Research Ethics Committee (GLY/01/14/HREC). The study was conducted in accordance with the principles of the Declaration of Helsinki and the standards of Good Clinical Practice as defined by the International Conference on Harmonisation. Written informed consent was obtained from all participants prior to commencement of the study. The use of human blood products for culture of P. falciparum and P. knowlesi was approved by the Griffith University Human Research Ethics Committee (BDD/02/14/HREC). As part of standard Australian Red Cross Blood Service practice, donors consent each time they donate blood or blood products for the use of their donation for research purposes.

\section{Consent for publication}

Consent to publish data from the study was obtained from all participants prior to commencement of the study.

\section{Competing interests}

$D S, X L, I E D, I R, J P, N W, S D, M H$ and $M G$ declare competing interests. At the time of this study, they were employees of Griffith University, which co-owns a patent family "Blood-Stage Malaria Vaccine". This patent family is related to the work described in this manuscript.

\section{Publisher's Note}

Springer Nature remains neutral with regard to jurisdictional claims in published maps and institutional affiliations.

\section{Author details}

${ }^{1}$ Institute for Glycomics, Griffith University, Parklands Drive, Southport, Queensland, Australia. ${ }^{2}$ Gold Coast University Hospital, 1 Hospital Blvd, Southport, Queensland, Australia. ${ }^{3}$ Sanaria Inc., Gaithersburg, MD, USA.

Received: 25 June 2018 Accepted: 11 September 2018

Published online: 08 October 2018

\section{References}

1. World Health Organisation. World malaria report 2015. In: World Health Organisation, editor. ; 2015

2. Sagara I, Dicko A, Ellis RD, Fay MP, Diawara SI, Assadou MH, Sissoko MS, Kone M, Diallo Al, Saye R, et al. A randomized controlled phase 2 trial of the blood stage AMA1-C1/Alhydrogel malaria vaccine in children in Mali. Vaccine. 2009;27(23):3090-8.

3. Ogutu BR, Apollo OJ, McKinney D, Okoth W, Siangla J, Dubovsky F, Tucker K, Waitumbi JN, Diggs C, Wittes J, et al. Blood stage malaria vaccine eliciting high antigen-specific antibody concentrations confers no protection to young children in Western Kenya. PLoS One. 2009;4(3):e4708.

4. Sirima SB, Cousens S, Druilhe P. Protection against malaria by MSP3 candidate vaccine. N Engl J Med. 2011;365(11):1062-4.

5. Olotu A, Fegan G, Wambua J, Nyangweso G, Awuondo KO, Leach A, Lievens M, Leboulleux D, Njuguna P, Peshu N, et al. Four-year efficacy of RTS, S/AS01E and its interaction with malaria exposure. N Engl J Med. 2013;368(12):1111-20.

6. Seder RA, Chang LJ, Enama ME, Zephir KL, Sarwar UN, Gordon IJ, Holman $L A$, James ER, Billingsley PF, Gunasekera A, et al. Protection against malaria by intravenous immunization with a nonreplicating sporozoite vaccine. Science. 2013;341(6152):1359-65.

7. Ishizuka AS, Lyke KE, DeZure A, Berry AA, Richie TL, Mendoza FH, Enama ME, Gordon IJ, Chang LJ, Sarwar UN, et al. Protection against malaria at 1 year and immune correlates following PfSPZ vaccination. Nat Med. 2016;22(6):614-23.

8. Sissoko MS, Healy SA, Katile A, Omaswa F, Zaidi I, Gabriel EE, Kamate B, Samake Y, Guindo MA, Dolo A, et al. Safety and efficacy of PfSPZ Vaccine against Plasmodium falciparum via direct venous inoculation in healthy malaria-exposed adults in Mali: a randomised, double-blind phase 1 trial. Lancet Infect Dis. 2017;17(5):498-509.

9. Lyke KE, Ishizuka AS, Berry AA, Chakravarty S, DeZure A, Enama ME, James ER, Billingsley PF, Gunasekera A, Manoj A, et al. Attenuated PfSPZ Vaccine induces strain-transcending $T$ cells and durable protection against heterologous controlled human malaria infection. Proc Natl Acad Sci U S A. 2017;114(10):2711-6. 
10. Epstein JE, Paolino KM, Richie TL, Sedegah M, Singer A, Ruben AJ, Chakravarty S, Stafford A, Ruck RC, Eappen AG, et al. Protection against Plasmodium falciparum malaria by PfSPZ Vaccine. JCI Insight. 2017;2(1):e89154.

11. Mordmuller B, Surat G, Lagler H, Chakravarty S, Ishizuka AS, Lalremruata A, Gmeiner M, Campo JJ, Esen M, Ruben AJ, et al. Sterile protection against human malaria by chemoattenuated PfSPZ vaccine. Nature. 2017;542(7642):445-9.

12. Stanisic DI, McCarthy JS, Good MF. Controlled human malaria infection: applications, advances, and challenges. Infect Immun. 2018;86(1):e00479-1.

13. Austin SC, Stolley PD, Lasky T. The history of malariotherapy for neurosyphilis. Modern parallels. JAMA. 1992;268(4):516-9.

14. Snounou G, Perignon JL. Malariotherapy--insanity at the service of malariology. Adv Parasitol. 2013;81:223-55.

15. Stanisic DI, Good MF. Whole organism blood stage vaccines against malaria. Vaccine. 2015;33(52):7469-75.

16. Purcell LA, Wong KA, Yanow SK, Lee M, Spithill TW, Rodriguez A. Chemically attenuated Plasmodium sporozoites induce specific immune responses, sterile immunity and cross-protection against heterologous challenge. Vaccine. 2008;26(38):4880-4.

17. Purcell LA, Yanow SK, Lee M, Spithill TW, Rodriguez A. Chemical attenuation of Plasmodium berghei sporozoites induces sterile immunity in mice. Infect Immun. 2008;76(3):1193-9.

18. Good MF, Reiman JM, Rodriguez IB, Ito K, Yanow SK, El-Deeb IM, Batzloff MR, Stanisic DI, Engwerda C, Spithill T, et al. Cross-species malaria immunity induced by chemically attenuated parasites. J Clin Invest. 2013;123:3353-62.

19. Raja Al, Cai Y, Reiman JM, Groves P, Chakravarty S, McPhun V, Doolan DL, Cockburn I, Hoffman SL, Stanisic DI, et al. Chemically attenuated bloodstage Plasmodium yoelii parasites induce long-lived and strain-transcending protection. Infect Immun. 2016;84(8):2274-88.

20. Reiman JM, Kumar S, Rodriguez IB, Gnidehou S, Ito K, Stanisic DI, Lee M, McPhun V, Majam V, Willemsen NM, et al. Induction of immunity following vaccination with a chemically attenuated malaria vaccine correlates with persistent antigenic stimulation. Clin Transl Immunol. 2018;7(4):e1015.

21. Sato A, McNulty L, Cox K, Kim S, Scott A, Daniell K, Summerville K, Price C, Hudson S, Kiakos K, et al. A novel class of in vivo active anticancer agents: achiral seco-amino- and seco-hydroxycyclopropylbenz[e]indolone (seco-CBI) analogues of the duocarmycins and CC-1065. J Med Chem. 2005:48(11):3903-18.

22. Su Z, Tam MF, Jankovic D, Stevenson MM. Vaccination with novel immunostimulatory adjuvants against blood-stage malaria in mice. Infect Immun. 2003;71(9):5178-87.

23. Demarta-Gatsi C, Smith L, Thiberge S, Peronet R, Commere PH, Matondo M, Apetoh L, Bruhns P, Menard R, Mecheri S. Protection against malaria in mice is induced by blood stage-arresting histamine-releasing factor (HRF)deficient parasites. J Exp Med. 2016;213(8):1419-28.

24. Aly AS, Downie MJ, Mamoun CB, Kappe SH. Subpatent infection with nucleoside transporter 1-deficient Plasmodium blood stage parasites confers sterile protection against lethal malaria in mice. Cell Microbiol. 2010;12(7):930-8.

25. D'Ombrain MC, Robinson LJ, Stanisic DI, Taraika J, Bernard N, Michon P, Mueller I, Schofield L. Association of early interferon-gamma production with immunity to clinical malaria: a longitudinal study among Papua New Guinean children. Clin Infect Dis. 2008;47(11):1380-7.

26. Robinson L, D'Ombrain M, Stanisic D, Taraika J, Bernard N, Richards J, Beeson J, Tavul L, Michon P, Mueller I, et al. Cellular tumour necrosis factor, gamma interferon, and interleukin- 6 responses as correlates of immunity and risk of clinical Plasmodium falciparum malaria in children from Papua New Guinea. Infect Immun. 2009;77(7):3033-43.

27. McCall MB, Hopman J, Daou M, Maiga B, Dara V, Ploemen I, NganouMakamdop K, Niangaly A, Tolo Y, Arama C, et al. Early interferon-gamma response against Plasmodium falciparum correlates with interethnic differences in susceptibility to parasitemia between sympatric Fulani and Dogon in Mali. J Infect Dis. 2010;201(1):142-52.

28. Luty AJ, Lell B, Schmidt-Ott R, Lehman LG, Luckner D, Greve B, Matousek P, Herbich K, Schmid D, Migot-Nabias F, et al. Interferon-gamma responses are associated with resistance to reinfection with Plasmodium falciparum in young African children. J Infect Dis. 1999;179(4):980-8.

29. Pombo DJ, Lawrence G, Hirunpetcharat C, Rzepczyk C, Bryden M, Cloonan $\mathrm{N}$, Anderson $\mathrm{K}$, Mahakunkijcharoen $\mathrm{Y}$, Martin LB, Wilson D, et al. Immunity to malaria after administration of ultra-low doses of red cells infected with Plasmodium falciparum. Lancet. 2002;360(9333):610-7.

30. De SL, Stanisic DI, van Breda K, Bellete B, Harris I, McCallum F, Edstein MD, Good MF. Persistence and immunogenicity of chemically attenuated blood stage Plasmodium falciparum in Aotus monkeys. Int J Parasitol. 2016;46(9):581-91.
31. Stanisic DI, Liu XQ, De SL, Batzloff MR, Forbes T, Davis CB, Sekuloski S, Chavchich M, Chung W, Trenholme K, et al. Development of cultured Plasmodium falciparum blood-stage malaria cell banks for early phase in vivo clinical trial assessment of anti-malaria drugs and vaccines. Malar J. 2015;14:143.

32. Stanisic DI, Gerrard J, Fink J, Griffin PM, Liu XQ, Sundac L, Sekuloski S, Rodriguez IB, Pingnet J, Yang Y, et al. Infectivity of Plasmodium falciparum in malaria-naive individuals is related to knob expression and cytoadherence of the parasite. Infect Immun. 2016;84(9):2689-96.

33. Rockett RJ, Tozer SJ, Peatey C, Bialasiewicz S, Whiley DM, Nissen MD, Trenholme K, Mc Carthy JS, Sloots TP. A real-time, quantitative PCR method using hydrolysis probes for the monitoring of Plasmodium falciparum load in experimentally infected human volunteers. Malar J. 2011;10:48.

34. Padley DJ, Heath AB, Sutherland C, Chiodini PL, Baylis SA, Collaborative Study G: Establishment of the 1st World Health Organization International Standard for Plasmodium falciparum DNA for nucleic acid amplification technique (NAT)-based assays. Malar J 2008, 7:139.

35. Mosha JF, Sturrock HJ, Greenhouse B, Greenwood B, Sutherland CJ, Gadalla N, Atwal S, Drakeley C, Kibiki G, Bousema T, et al. Epidemiology of subpatent Plasmodium falciparum infection: implications for detection of hotspots with imperfect diagnostics. Malar J. 2013;12:221.

36. Currier J, Sattabongkot J, Good MF. 'Natural' T cells responsive to malaria: evidence implicating immunological cross-reactivity in the maintenance of TCR alpha beta+ malaria-specific responses from non-exposed donors. Int Immunol. 1992;4(9):985-94.

37. Kremsner PG, Winkler S, Brandts C, Wildling E, Jenne L, Graninger W, Prada J Bienzle U, Juillard P, Grau GE. Prediction of accelerated cure in Plasmodium falciparum malaria by the elevated capacity of tumor necrosis factor production. Am J Trop Med Hyg. 1995;53(5):532-8.

38. Grau GE, Taylor TE, Molyneux ME, Wirima JJ, Vassalli P, Hommel M, Lambert $\mathrm{PH}$. Tumor necrosis factor and disease severity in children with falciparum malaria. N Engl J Med. 1989;320(24):1586-91.

39. Kern P, Hemmer CJ, Van Damme J, Gruss HJ, Dietrich M. Elevated tumor necrosis factor alpha and interleukin-6 serum levels as markers for complicated Plasmodium falciparum malaria. Am J Med. 1989;87(2):139-43.

40. Day NP, Hien TT, Schollaardt T, Loc PP, Chuong LV, Chau TT, Mai NT, Phu $\mathrm{NH}$, Sinh DX, White NJ, et al. The prognostic and pathophysiologic role of pro- and antiinflammatory cytokines in severe malaria. J Infect Dis. 1999; 180(4):1288-97.

41. Freitas do Rosario AP, Langhorne J. T cell-derived IL-10 and its impact on the regulation of host responses during malaria. Int J Parasitol. 2012;42(6):549-55.

42. Lindenstrom T, Agger EM, Korsholm KS, Darrah PA, Aagaard C, Seder RA Rosenkrands I, Andersen P. Tuberculosis subunit vaccination provides longterm protective immunity characterized by multifunctional CD4 memory $T$ cells. J Immunol. 2009;182(12):8047-55.

43. Darrah PA, Patel DT, De Luca PM, Lindsay RW, Davey DF, Flynn BJ, Hoff ST, Andersen P, Reed SG, Morris SL, et al. Multifunctional TH1 cells define a correlate of vaccine-mediated protection against Leishmania major. Nat Med. 2007;13(7):843-50.

44. Roestenberg M, McCall M, Hopman J, Wiersma J, Luty AJ, van Gemert GJ, van de Vegte-Bolmer M, van Schaijk B, Teelen K, Arens T, et al. Protection against a malaria challenge by sporozoite inoculation. N Engl J Med. 2009; 361(5):468-77.

45. Edstein MD, Kotecka BM, Anderson KL, Pombo DJ, Kyle DE, Rieckmann KH, Good MF. Lengthy antimalarial activity of atovaquone in human plasma following atovaquone-proguanil administration. Antimicrob Agents Chemother. 2005;49(10):4421-2.

Ready to submit your research? Choose BMC and benefit from:

- fast, convenient online submission

- thorough peer review by experienced researchers in your field

- rapid publication on acceptance

- support for research data, including large and complex data types

- gold Open Access which fosters wider collaboration and increased citations

- maximum visibility for your research: over $100 \mathrm{M}$ website views per year

At BMC, research is always in progress.

Learn more biomedcentral.com/submission 